\title{
Shallow tectonic tremor activities in Hyuga-nada, Nankai subduction zone, based on long-term broadband ocean bottom seismic observations
}

\author{
Yusuke Yamashita ${ }^{1^{*}}$ (D) Masanao Shinohara ${ }^{2}$ and Tomoaki Yamada ${ }^{2}$
}

\begin{abstract}
The study of slow earthquake activity, which occurs in the shallow and deep sides of seismogenic zone, is crucial for understanding subduction zones, including variations in frictional properties with depth and interplate coupling. Observations at the seafloor are necessary, particularly for shallow slow earthquakes occurring in offshore areas; however, few observations of such activity have been made. We conducted long-term seismic observations on the seafloor in the Hyuga-nada region, located at the western end of the Nankai Trough, to characterize shallow lowfrequency tremor activity from 2014 to 2017. Although these observations lasted for only a few years, the occurrence frequency of shallow tremors in Hyuga-nada was lower than that of deep tremors in the Nankai Trough, and major activity involving migration occurred only once every two or more years. In contrast, minor activity with a duration of a few days occurred several times a year. Major activities in 2015 were accompanied by migration similar to those in 2013. The tremors in 2013 were characterized by south to north migration at a rate of 30-60 km/day. However, the tremors in 2015 were characterized by west to east migration, and the activity area extended further to the east. The migration rates were also much slower (several to $20 \mathrm{~km} /$ day) than in 2013. These different migration properties likely reflect the state of interplate coupling in the down-dip side of shallow slow earthquake area. Minor activity was identified, including tremors triggered by the 2015 Nepal and 2016 Kumamoto earthquakes. Activity occurred mainly in the focal regions of major activities. Very-low-frequency earthquakes (VLFEs) occurred concurrently with tremors, and their epicenters coincided within the margin of error. However, the VLFEs were mostly peripheral to the shallow tremor concentration zones. This indicates that minor heterogeneities in frictional properties are present along the shallow plate boundary.
\end{abstract}

Keywords: Slow earthquake, Shallow low-frequency tremor, Ocean bottom seismometer, Long-term ocean bottom observation, Nankai subduction zone, Hyuga-nada

\section{Introduction}

During the last two decades, different slow earthquakes, including tectonic low-frequency tremors, very-lowfrequency earthquakes (VLFEs), and episodic slow slip

\footnotetext{
*Correspondence: yamac@rcep.dpri.kyoto-u.ac.jp

${ }^{1}$ Miyazaki Observatory, Disaster Prevention Research Institute, Kyoto

University, 3884 Kaeda, Miyazaki 889-2161, Japan

Full list of author information is available at the end of the article
}

events (SSEs), have been observed on the downward segments of the seismogenic megathrust boundaries in subduction zones (hereafter termed deep slow earthquakes) (e.g., Obara and Kato 2016; Schwartz and Rokosky 2007). These earthquakes revealed the transition between shallow brittle failure and deep creeping motion. At shallow plate boundaries, VLFEs have been reported in landbased observations (e.g., Obara and Ito 2005). In recent years, seafloor observations have also been conducted 
and cable-based seafloor monitoring systems have been constructed, thereby enabling the observation of shallow slow earthquakes (Annoura et al. 2017; Araki et al. 2017; Ito et al. 2015; Nishikawa et al. 2019; Obana and Kodaira 2009; Ohta et al. 2019; Plata-Martinez et al. 2021; Tanaka et al. 2019; Todd et al. 2018; Tonegawa et al. 2020; Wallace et al. 2016; Yamashita et al. 2015).

Yamashita et al. (2015) investigated the detailed properties of shallow low-frequency tremors (shallow tremors) in the Hyuga-nada region at the western end of the Nankai Trough, Japan, using ocean bottom observations of seismicity near the trench (Fig. 1). Complete episodes of shallow tremors that lasted up to a month were detected that exhibited migration properties similar to those of deep tremors. This activity was also linked to shallow VLFE activity, as shown by data acquired using a land-based broadband seismic network. Tremors and VLFEs often coincide, and their migration patterns resemble deep tremors during episodic tremor and slip (ETS) events (e.g., Ito et al. 2007). This similarity suggests that tremors at this shallow plate boundary are coupled with VLFEs and short-term SSEs (Yamashita et al. 2015). Analyses of 2010 activity by Asano et al. (2015) revealed a similar migration pattern for shallow VLFEs in the Hyuga-nada region. According to both studies, the shallow and deep slow earthquake activity occurred repeatedly in the same area.

Understanding the characteristics of shallow tremors is essential for understanding the spatiotemporal heterogeneity of interplate coupling along the shallow part of a plate boundary. However, few studies of shallow tremor activity have been conducted; thus, the characteristics of such activity are not well known. The characteristics of the shallow tremors in the Hyuga-nada region were initially reported by Yamashita et al. (2015); however, the study lacked information regarding the activity history and cycle. This lack of information is mainly because the details of shallow tremor activity cannot be acquired using land-based observations. Such activity can only be elucidated using seafloor observations.

Monitoring shallow tremors can provide information on the spatiotemporal changes in crustal activity along shallow plate boundaries at a kilometer scale. This also enables the indirect monitoring of SSEs, which are associated with shallow tremor activity. Thus, investigating shallow tremor characteristics is essential for understanding the spatiotemporal variations in interplate coupling. However, this requires long-term monitoring of shallow tremor activity, owing to a limited current knowledge of their regularity.

In this study, we report on continuous seafloor observations, obtained using short-period and broadband ocean bottom seismometers since 2014, to clarify the nature of shallow slow earthquakes in the Hyuga-nada region and to understand their universality and regional characteristics. We obtained detailed source locations of the shallow tremors and discuss the spatiotemporal characteristics of their activity, as well as their relationship with VLFEs and interplate coupling in the Hyuga-nada region.

\section{Observations}

Long-term ocean bottom seismological monitoring in the focal area of shallow tremors began in March 2014. The monitoring network comprises pop-up-type ocean bottom seismometers (OBSs), which are mainly short-period long-term ocean bottom seismometers (LOBS) and two broadband ocean bottom seismometers (BBOBS). The OBSs consist of a spherical titanium housing that contains a sensor with a mechanical leveling unit, lithium batteries, a data recorder, and an acoustic transponder (Kanazawa et al. 2009). This system is suitable for longterm ( $>1$ year) continuous observations on the seafloor. The three-component velocity-type sensors used in the LOBS and BBOBS are Lennartz LE3D-lite (natural frequency $=1 \mathrm{~Hz}$ ) and Guralp Systems CMG-3 T (natural period $=360 \mathrm{~s}$ ) sensors, respectively. The seismometer signals were recorded continuously on a hard-disk drive or SD card after an analog-digital conversion using a 20or 24-bit resolution and a sampling frequency of $200 \mathrm{~Hz}$. The clock reading for each OBS was compared with that of a GPS clock prior to installation and after recovery, and the time stamps were corrected, as they had an accuracy less than that of the sampling frequency.

Owing to electrical power limitations, the OBSs were retrieved and re-deployed annually. Therefore, the observations were divided into the following periods: March 2014-January 2015 (1st period), January 2015-January 2016 (2nd period), and January 2016-February 2017 (3rd period). The number of instruments employed depended on the observation period. The locations of all OBS stations utilized for continuous monitoring during the study are shown in Fig. 1, and the OBS networks used during each observation period are shown in Additional file 1: Figure S1.

\section{Waveform characteristic observed by LOBS and BBOBS}

Signals recorded using the OBSs were all satisfactory and were available for analysis throughout the monitoring period. Example waveforms for each OBS station during the second observation period are shown in Fig. 2a. The black trace shows the waveform of the tremor band at each station. The characteristic spindle-shaped wave group is the shallow tremor. Two BBOBSs (OBSs 08 and 10) installed during this period recorded clear shallow tremor and VLFE signals, indicated by the black and red trace in Fig. 2a, 


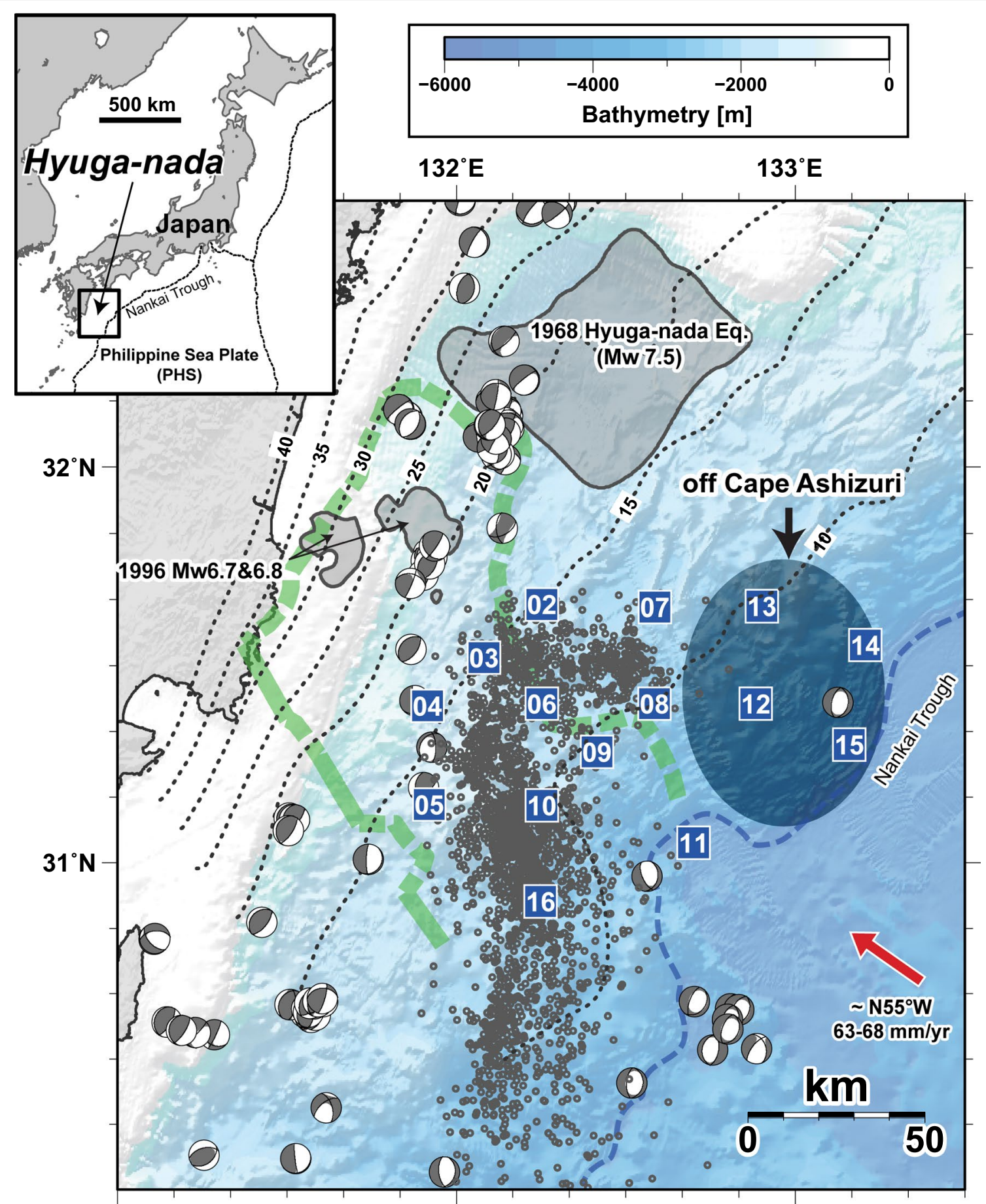

Fig. 1 Locations of all OBS stations used during the observation periods in the Hyuga-nada region and the simplified regional tectonic setting. Blue squares and numbers represent OBS station locations and numbers, respectively. Gray circles indicate shallow tremor activity in 2013 (Yamashita et al. 2015). Black dotted lines are depth contours of the top of the Philippine Sea Plate (Nakanishi et al. 2018). Gray shaded areas represent the coseismic slip area of the 1968 Hyuga-nada and 1996 earthquakes (Yagi et al. 1998, 1999). The light green bold line delineates the outer edge of the subducted Kyushu-Palau Ridge (Yamamoto et al. 2013) 


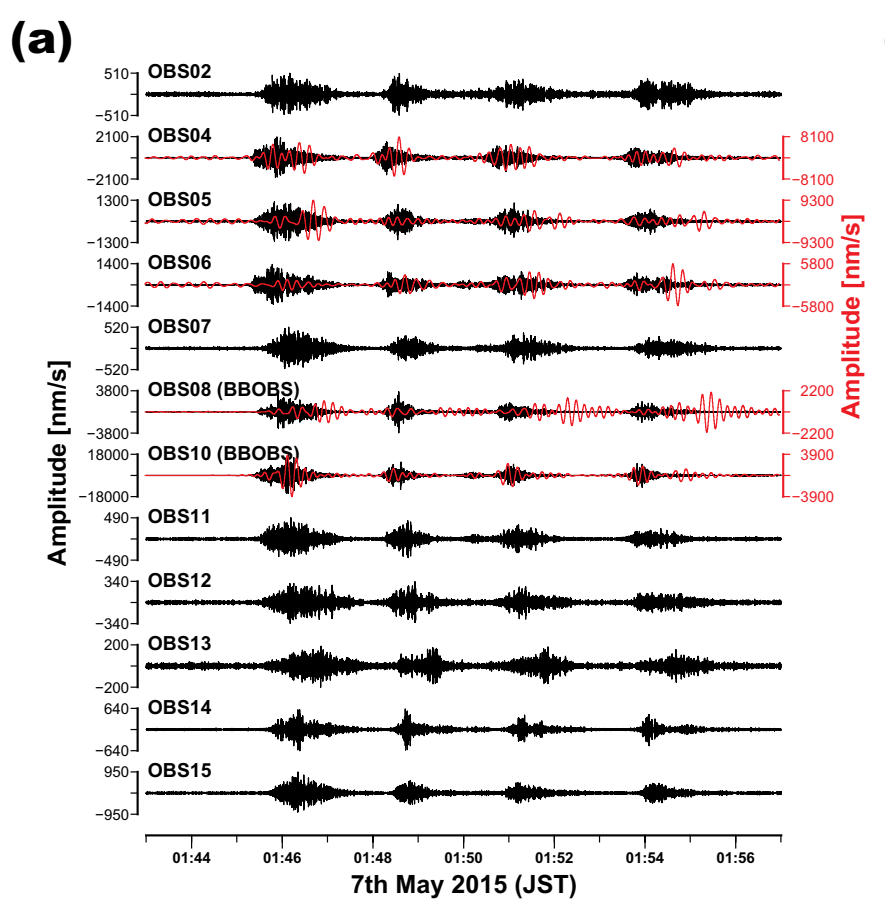

(b)

\section{OBS10 (BBOBS: CMG-3T 360 s)}

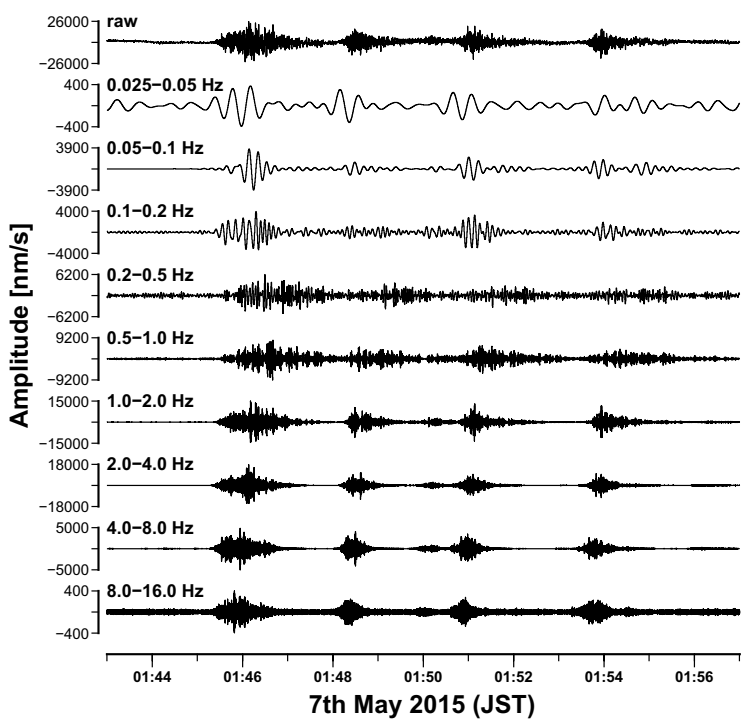

Fig. 2 Example waveform from the 2nd observation period showing: a the bandpass-filtered waveform in the tremor (2-4 Hz: black) and the VLFE (0.05-0.1 Hz: red) bands for 14 stations (numbers indicate the OBS stations shown in Fig. 1). The instrumental responses have been corrected. Red traces (VLFE band) are plotted only for stations where a signal was obtained above the noise level. Each trace was normalized based on the maximum amplitude and $\mathbf{b}$ bandpass-filtered waveforms for different bands observed by the BBOBS (OBS 10). The uppermost waveform is the raw data, while the others were filtered using the bands displayed to the left

respectively. Each red trace was corrected for instrumental response, and a $0.05-0.1 \mathrm{~Hz}$ bandpass filter was applied. Some of the LOBSs recorded VLFE signals (Stations 04, 05, and 06), although these are short-period seismometers with a natural frequency of $1 \mathrm{~Hz}$. A signal is observed if it sufficiently exceeds the instrumental noise $(\sim 2000 \mathrm{~nm} / \mathrm{s})$, indicating that under suitable conditions, tremors and VLFEs can be observed simultaneously by the LOBS.

Although microseism noise usually conceals signals in the $0.1-1 \mathrm{~Hz}$ band, clear tremor and VLFE signals were observed in this range (Fig. 2b). Kaneko et al. (2018) reported the first direct observation of continuous broadband signals in the $0.02-8 \mathrm{~Hz}$ range based on data from the Dense Ocean floor Network System for Earthquakes and Tsunamis (DONET), which is located off the Kii Peninsula in the Nankai subduction zone. The shallow slow earthquakes in the Hyuga-nada region represent a broadband phenomenon known as "broadband slow earthquakes" (Kaneko et al. 2018) that can be explained by the Brownian slow earthquake model (Ide 2008), similar to those events observed off the Kii Peninsula.

\section{Data analysis}

To identify the shallow tremor locations, the envelope cross-correlation method (e.g., Obara 2002) was used, as well as a procedure similar to that of Yamashita et al. (2015) for the Hyuga-nada region using OBS data. In this study, the focal depth was fixed based on the plate geometry model (Nakanishi et al. 2018) and a homogenous structure with an S-wave velocity of $3.0 \mathrm{~km} / \mathrm{s}$ was assumed.

A root-mean-square (RMS) envelope was created from the bandpass-filtered waveforms in the $2-4 \mathrm{~Hz}$ band. The RMS envelope waveform was resampled to $20 \mathrm{~Hz}$ after the application of a $0.2-\mathrm{Hz}$ low-pass filter. Cross-correlation coefficients were calculated within a time window of $120 \mathrm{~s}$ for station pairs, and lag times at the maximum correlation coefficients served as the relative differential time data for correlation coefficients greater than 0.70 . The optimal value was obtained using a grid search method associated with step-wise grid interval decreases. The duration of each tremor was obtained using the method described by Ohta et al. (2019), while the corresponding error was estimated 
from the $1 \mathrm{~dB}$ area of the variance reduction (VR) based on the method described by Maeda and Obara (2009).

Since the events included ordinary earthquakes, duplicate events were removed through comparisons with data from the Japan Meteorological Agency (JMA) Unified Earthquake Catalog. In addition, events with durations less than $20 \mathrm{~s}$, errors greater than $15 \mathrm{~km}$, and differential travel time residuals more than $1.5 \mathrm{~s}$ were also removed. Finally, owing to the nature of tremors, spatiotemporal clustering was performed (e.g., Ohta et al. 2019), which included at least 5 events in a $15-\mathrm{km}$ radius within $3 \mathrm{~h}$ preceding and following the event. Using these methods, false signals, including ordinary earthquake swarms, were removed from the catalog.

\section{Results}

Although the monitoring conducted by Yamashita et al. (2015) lasted for less than 4 years, the occurrence frequency of shallow tremors in the Hyuga-nada region appears to be lower than that of deep tremors in the Nankai Trough (e.g., Obara 2010). In addition, a major episode of activity that lasted for a few months and involved migration was recorded only once in two or more years, while minor activity with a duration of a few days occurred many times each year.

To evaluate the spatiotemporal characteristics of the shallow tremors, the recorded activity was partitioned into six episodes covering the monitoring period. Spatial distributions of shallow tremors for all episodes recorded by the present study, as well as those described by (Yamashita et al. 2015), are shown in Fig. 3, while the distributions of each episode are shown in Fig. 4.

\section{Minor ambient tremor activity (Episodes 1, 2, and 3)}

Episode 1 involved activity up to a point where the tremors stopped migrating northward and turned sharply eastward in 2013 (Fig. 4a). During Episode 2, minor activity occurred near the trench axis (Fig. 4b), while activity in Episode 3 occurred in almost the same location (Fig. 4c) as the activity in Episode 1 . The spatial distributions of the shallow tremors during Episodes 1, 2, and 3 were limited and characterized by unclear migration (Additional file 1: Figs. S3, S4, S5). Activity that occurred during these three episodes was not triggered by any seismic event, but instead began spontaneously.

\section{Minor triggered tremor activity (Episodes 4 and 6)}

Minor activity that occurred in Episode 4 began after the April 25, 2015 (JST) Nepal Earthquake (Mw 7.8) (Fig. 4d) and converged within two days (Additional file 1: Fig. S6). Similarly, activity that occurred in Episode 6 began after the April 16, 2016 Kumamoto Earthquake (Mw 7.0) (Fig. 4f), which occurred $\sim 200 \mathrm{~km}$ from the study area. For both of these periods, the activity proceeded intermittently for approximately 2 weeks (Additional file 1: Fig. S7). Despite the differences in seismicity levels, the distributions of shallow tremors during Episodes 4 and 6 appeared to overlap (Fig. 4d, f). However, the locations of the triggered tremors were generally limited, suggesting that the focal areas of Episodes 4 and 6 were very sensitive to stress changes.

Although Episode 6 began on April 17 (Additional file 1: Fig. S7), further analysis of the waveforms at each OBS station revealed a tremor signal at OBS 12 at approximately 03:20 on April 16 (approximately $3 \mathrm{~h}$ after the main shock). However, most of the tremor signals were either masked or contaminated by aftershocks for approximately 2 days after the earthquake. In addition, shallow tremors occurred simultaneously in multiple locations. Nevertheless, because only five observation points were available, and because the OBS stations were slightly wider apart compared to other periods (Additional file 1: Fig. S1c), the observation network was inadequate for determining the hypocenter. Owing to the limited events available for hypocenter determination, Episode 6 could not be characterized entirely accurately.

\section{Major ambient tremor activity (Episode 5)}

Episode 5 occurred during the second observation period and encompassed a wider area than the other episodes (Fig. 4e). In comparison with the 2013 activity, events in Episode 5 extended farther to the east, although some overlap occurred between the western section of Episode 5 and the eastern section of the 2013 activity (Additional file 1: Fig. S2). The area south of the monitoring network was excluded from the catalog because of large estimation errors. According to the spatiotemporal variations in activity during Episode 5 (Fig. 4h), migration from west to east occurred. The activity initiated near the areas of Episodes 1 and 3, and stopped near the area where the 2013 activity terminated after eastward migration (around OBS 08) (Fig. 4g). Following the Ogasawara Earthquake, a major (Mw 7.8) deep focused earthquake occurred at

(See figure on next page.)

Fig. 3 Shallow tremors observed using the OBSs during the observation period showing the a epicenter distribution of all shallow tremors obtained in this study (red circles) and all OBS stations used for the observation period (blue squares). Other contours and symbols are the same as those in Fig. 1. b Spatiotemporal plot projected on the W-E line shown in $\mathbf{a}$. based on JST time (UTC+9). Blue filled stars indicate the timing of three major earthquakes that affected the shallow tremor activity. The shallow tremor activity is divided into Episodes (ep.) $1-6$ according to the characteristics of the activity 
(a)

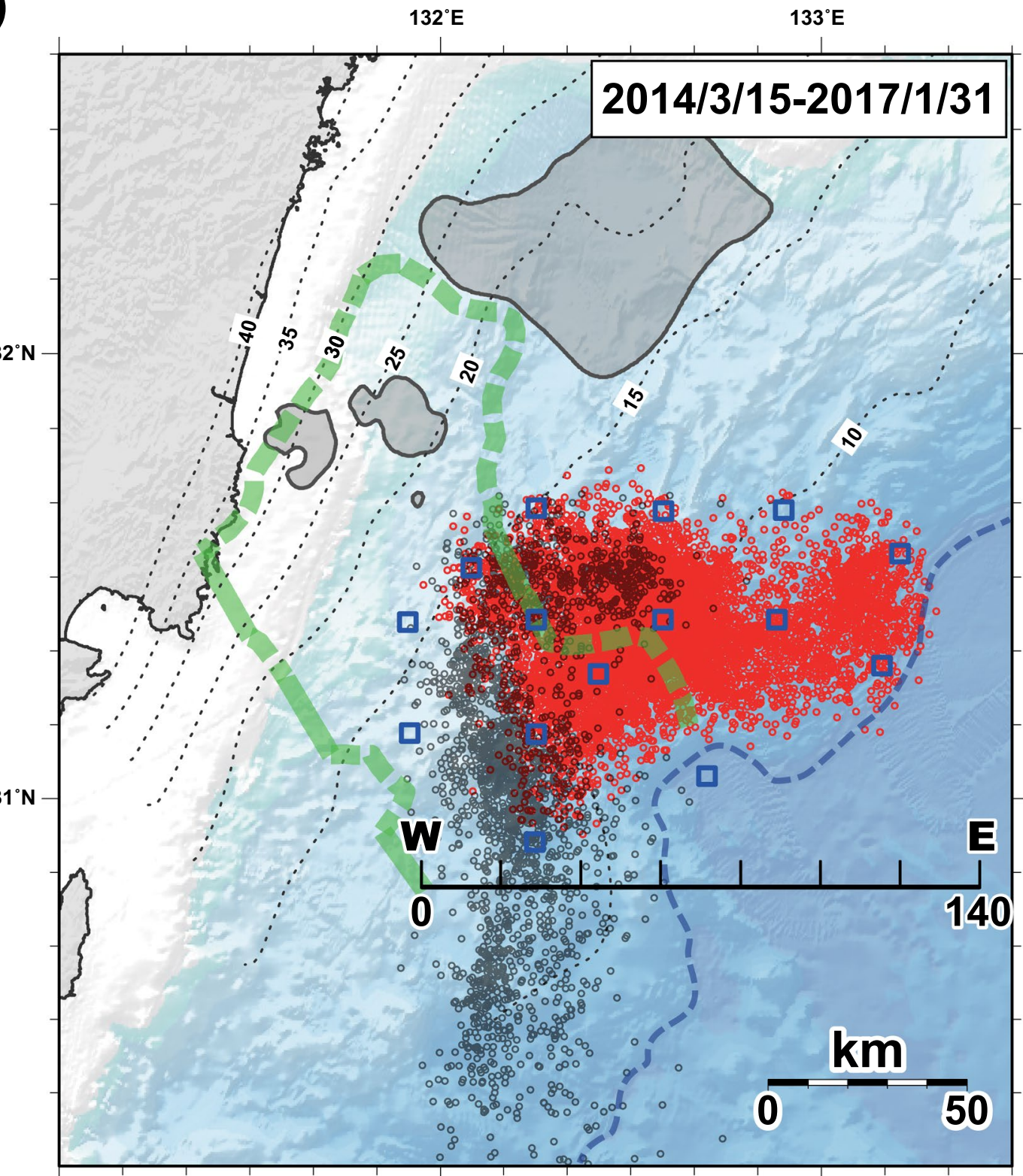

(b)

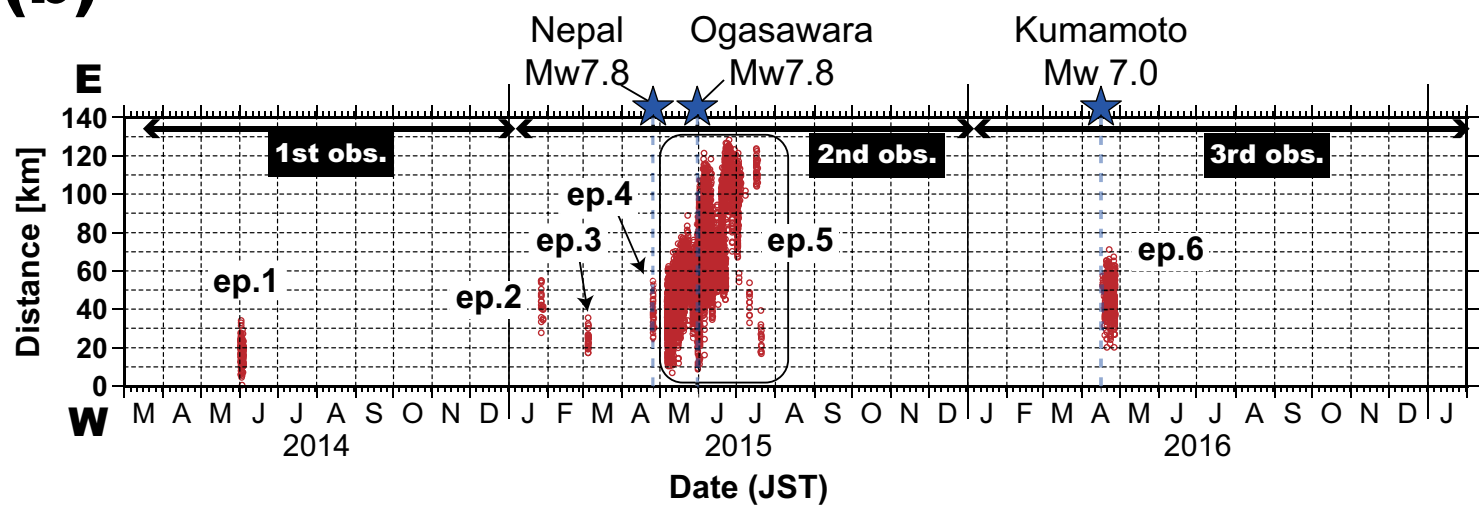

Fig. 3 (See legend on previous page.) 
20:24 (JST) on May 30, 2015 and activity spread eastward to the area off Cape Ashizuri (Fig. 4g and h).

Onshore observations were used to confirm the largescale migration of shallow VLFEs off Cape Ashizuri in 2003 and 2010 (Asano et al. 2015; Hirose et al. 2010). This activity occurred synchronously with long-term SSE activity in the Bungo Channel, which occurs on an approximately 6 years cycle. However, during Episode 5 , no large-scale long-term SSEs were recorded in the Bungo Channel. The VLFE activity off Cape Ashizuri was also confirmed using onshore observations, although there were fewer recorded events than in 2003 and 2010 (Uchida et al. 2020). Therefore, activity during Episode 5 differed from those in 2003 and 2010, which occurred synchronously with long-term SSE activity in the Bungo Channel.

\section{Discussion}

\section{Comparison of the $\mathbf{2 0 1 3}$ and $\mathbf{2 0 1 5}$ migration properties}

The 2013 activity migrated from south to north, then changed to migrate eastward, and stopped after crossing the subducted Kyushu-Palau Ridge (Fig. 1). Typical along-strike migration rates of the 2013 activity ranged from 30 to $60 \mathrm{~km}$ /day (Yamashita et al. 2015), which are significantly faster than those of deep tremors (Houston et al. 2011; e.g., Obara 2010), but slower than the rapid tremor reversal (RTR) rates of $160-400 \mathrm{~km} / \mathrm{d}$ (Houston et al. 2011) and streak over $100 \mathrm{~km} / \mathrm{h}$ in the slip direction (e.g., Ghosh et al. 2010; Shelly et al. 2007). Conversely, typical along-strike migration rates of the 2015 activity (Episode 5) were initially slow (a few $\mathrm{km} /$ day), then accelerated to $\sim 20 \mathrm{~km} /$ day as the activity area expanded to the east (Fig. 4h and Additional file 1: Fig. S2), although the rates remained lower than those of the 2013 activity.

Migration rates reported for shallow tremors in other regions range from a few to $20 \mathrm{~km} /$ day (e.g., Annoura et al. 2017; Araki et al. 2017; Nishikawa et al. 2019; Ohta et al. 2019; Tanaka et al. 2019). Therefore, the migration rates associated with the active region in 2013 were unusually high, whereas those for the 2015 active region were within the range for shallow tremors. According to Yamashita et al. (2015), differences in interplate coupling in the deep portion of the shallow tremor region affect the extent of shallow tremor activity. Shallow VLFE activity also exhibits an anticorrelative relationship with the spatial distribution of the interplate coupling ratio (Baba et al. 2020). In the area off Cape Ashizuri, the deep portion of the shallow tremor region includes a locked zone associated with the 1968 Hyuga-nada Earthquake (Mw 7.5) (Fig. 1). Similar characteristics were observed offshore of the Kii Peninsula (e.g., Annoura et al. 2017; Araki et al. 2017) and in the Sanriku and Tokachi regions (e.g., Nishikawa et al. 2019; Tanaka et al. 2019). In contrast, the deep portion of the 2013 shallow tremor region is characterized by a creeping megathrust (e.g., Wang and Bilek 2014; Yamashita et al. 2012). Migration rates of the shallow tremors may increase in regions without a prominent locked zone in the deep portion (Fig. 5). Although the rupture velocity of a fault is theoretically and numerically dependent on a number of factors, including stress state, fault strength, and pore pressure (e.g., Ando et al. 2012; Luo and Liu 2021), the stress shadow effect due to the locked zone (e.g., Ariyoshi et al. 2014; Bürgmann et al. 2005) is dominant on a regional scale.

Simulations have also suggested that shallow VLFE activity occurs more frequently than that of deep VLFEs during the pre-seismic stage of a simulated megathrust earthquake due to a partial weakening of the coupling around the locked zone (Ariyoshi et al. 2014). During this stage, shallow VLFEs will occur in the region where there is little or no VLFE activity and migrate along strike. Shallow tremors also exhibit this behavior. Therefore, if we understand the general properties of shallow tremor activity, the migration rates of the shallow tremors and the extents of their activities can be used for monitoring the spatiotemporal variations in interplate coupling.

\section{Implications of triggered shallow tremor}

Activity during both Episodes 4 and 6 was triggered by large earthquakes (Additional file 1: Figs. S6 and S7), which differed from spontaneous teleseismic waves associated with deep tremors (e.g., Chao and Obara 2016; Miyazawa and Mori 2005; Miyazawa and Brodsky 2008), and continued after the teleseismic waves (Fig. 5c, d). A body and/or surface wave associated with a large earthquake likely temporarily altered the pore fluid pressures in the tremor source region or triggered a small-scale SSE, thereby maintaining the activity after the surface wave. A similar situation associated with SSE activity off the Kii Peninsula was reported after the 2016 off Mie prefecture earthquake and the 2016 Kumamoto earthquake (Annoura et al. 2017; Araki et al. 2017; Nakano et al.

\footnotetext{
(See figure on next page.)

Fig. 4 Spatiotemporal evolution of shallow tremors during each episode. a-f Circles in red and black dots represent shallow tremors and shallow VLFEs (Tonegawa et al. 2020), respectively. The episode duration is displayed in the upper right corner of each figure. Blue squares indicate OBS stations used for monitoring during each episode. Other contours and symbols are the same as those in Fig. 1. g Spatial distribution of activity before and after the May 30, 2015 Ogasawara Earthquake (Mw 7.8) during Episode 5. The left and right panels show the epicenter distributions before and after the Mw 7.8 earthquake, respectively. $\mathbf{h}$ Spatiotemporal plot of shallow tremors during Episode 5 projected on the W-E cross section shown in Fig. The star indicates the timing of the Ogasawara Earthquake (Mw 7.8) and the event colors correspond to those in $\mathbf{g}$
} 

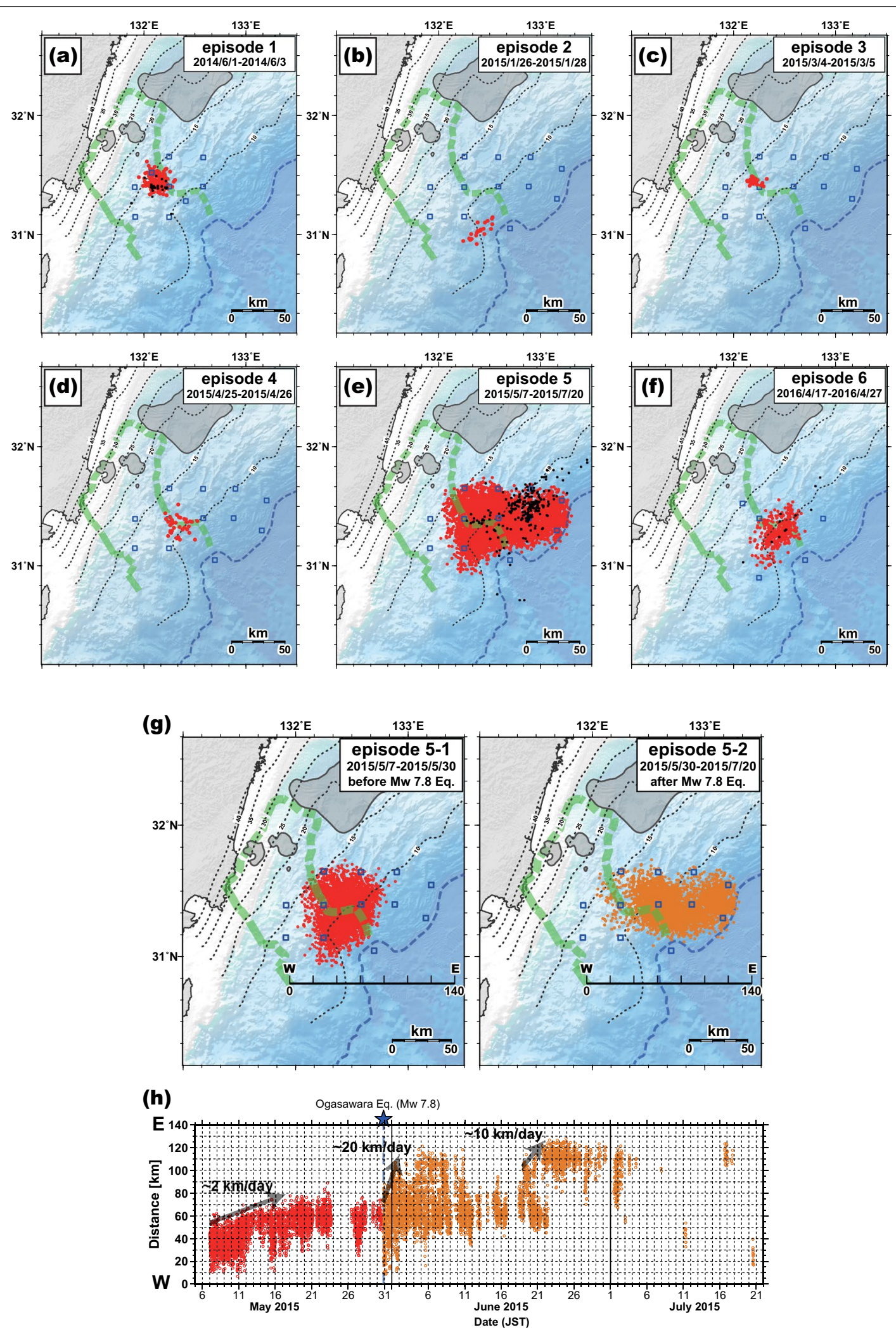

Fig. 4 (See legend on previous page.) 


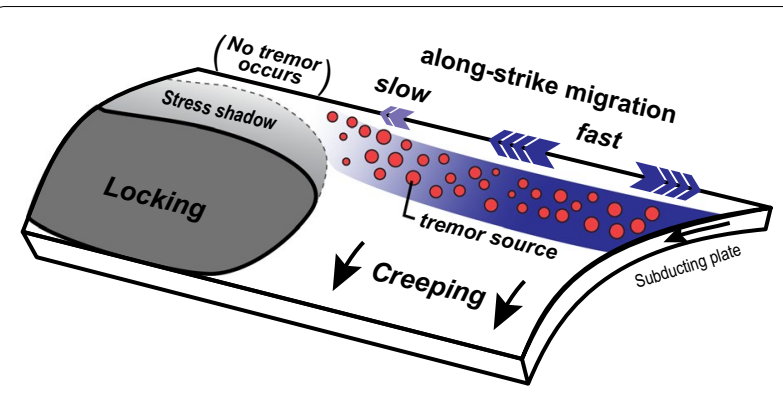

Fig. 5 Diagram of the relationship between interplate coupling and shallow tremor activity. When the boundary is creeping, shallow tremors can migrate along strike at a high rate. When the boundary is locked, tremors are less likely to migrate along strike due to the stress shadow effect

2018). Prolonged activity related to an SSE compared to that of a deep slow earthquake suggests that the effects of stress perturbations caused by major earthquakes likely last longer in shallow regions than in the deep regions of a plate boundary. This may be due to the widely different temperature and pressure conditions in the shallow and deep portions of the plate boundary, as well as variations in water content and the permeability of the rocks that comprise the plate boundary.

\section{Shallow tremor, VLFE, and long-term SSE comparisons}

Yamashita et al. (2015) found that shallow tremors and VLFEs occurred simultaneously in 2013, although their observations were based on seafloor data for tremors and land data for the VLFEs. In this study, shallow tremors and VLFEs were monitored using identical instruments installed on the seafloor. Therefore, we observed that tremors and VLFEs occurred almost synchronously after 2014.

Tonegawa et al. (2020) obtained the epicenters of shallow VLFEs by applying the envelope cross-correlation method to waveforms at frequencies from 0.1 to $0.15 \mathrm{~Hz}$. A comparison of the locations of the shallow tremors and VLFEs during each episode is shown in Fig. 4. VLFEs can only be detected for relatively large events; thus, even if many small VLFEs occurred, they will be not located. Therefore, the VLFEs shown in Fig. 4 comprise a particularly large event. Owing to differences in the frequency bands and source event sizes between the shallow tremors and VLFEs, a direct correspondence is unexpected. However, their locations are consistent within an estimated error range of a few to tens of $\mathrm{km}$. This is supported by the frequency characteristics of the observed waveforms, as shown in Fig. 2.

During Episodes 1 and 5 (Fig. 4a, e), VLFEs occurred in areas with few shallow tremors, including the edge of the shallow tremor source region. Although seismic waves associated with different frequency bands than those of tremors and VLFEs are likely released through a slow earthquake source process on a large scale, closer examination suggests that the sources of the tremors and VLFEs differ slightly. This difference can be attributed to minor heterogeneities in the frictional properties along the shallow plate boundary. Where VLFEs are concentrated with little tremor, interplate coupling is considered to be relatively strong during inter-seismic periods.

GNSS-A observations captured long-term SSEs along the shallow boundaries of the Nankai Trough (Yokota and Ishikawa 2020). A long-term shallow SSE was reported in the Hyuga-nada region in 2015 and off Cape Ashizuri in 2016. These events coincide with the timing of Episode 5. However, the 2003 and 2010 activity cannot be comparable directly because GNSS-A observation had not started yet. However, the differences in the extents of the long-term shallow SSE in the Hyuga-nada region likely impacted slow earthquake activity from the Hyuga-nada region to off Cape Ashizuri. Further seafloor seismological and geodetic observations are required to improve the source determination accuracy for both tremors and VLFEs, and for understanding the relationships and interactions between shallow slow earthquakes.

\section{Conclusions}

In this study, we reported on seafloor observations used to investigate shallow tremor activity in the Hyuganada region from 2014 to 2017 . The frequency of shallow tremors was lower than that of deep tremors in the Nankai Trough. Six episodes of activity were observed and were associated with the following characteristics: minor ambient tremor activity (Episodes 1, 2, and 3 ), minor triggered tremor activity (Episodes 4 and 6), and major ambient tremor activity associated with clear migration (Episode 5). Major activity occurred only once every two or more years, while minor activity occurred a few times annually. Source regions of the 2013 and Episode 5 activity overlapped partially, but the latter activity expanded eastward. Along-strike migration rates of the $2013(30-60 \mathrm{~km} /$ day $)$ and Episode 5 activity (a few $\mathrm{km} /$ day to $20 \mathrm{~km} /$ day) differed widely, with slower migration rates in Episode 5, although the ranges were similar to those reported for other regions. The difference in the migration rate likely reflects differences in interplate coupling in the deeper portion. Monitoring shallow tremors could be useful for monitoring spatiotemporal changes in interplate coupling in the shallow part of the plate boundary. A comparison of shallow tremor and VLFE distributions indicates that their epicenters coincided, within the margin of error. However, further examination revealed that the shallow VLFE sources were in located areas with low tremor 
epicenter densities and at the edges of these areas. This difference can be attributed to minor heterogeneities in frictional properties within the shallow part of the plate boundary. For a better understanding of the general and regional characteristics of shallow slow earthquakes and interplate coupling in the shallow part of the plate boundary, continuous seafloor monitoring and comparison with different subduction zones is required.

\begin{abstract}
Abbreviations
VLFE: Very-low-frequency earthquake; OBS: Ocean bottom seismometer; LOBS: Long-term ocean bottom seismometer; BBOBS: Broadband ocean bottom seismometer; SSE: Slow slip event; ETS: Episodic tremor and slip; RMS: Root-mean-square; RTR: Rapid tremor reversal; IST: Japan standard time; Mw: Moment magnitude; DONET: Dense Ocean floor Network System for Earthquakes and Tsunamis; ERI: Earthquake Research Institute; JMA: Japan Meteorological Agency.
\end{abstract}

\section{Supplementary Information}

The online version contains supplementary material available at https://doi. org/10.1186/s40623-021-01533-x.

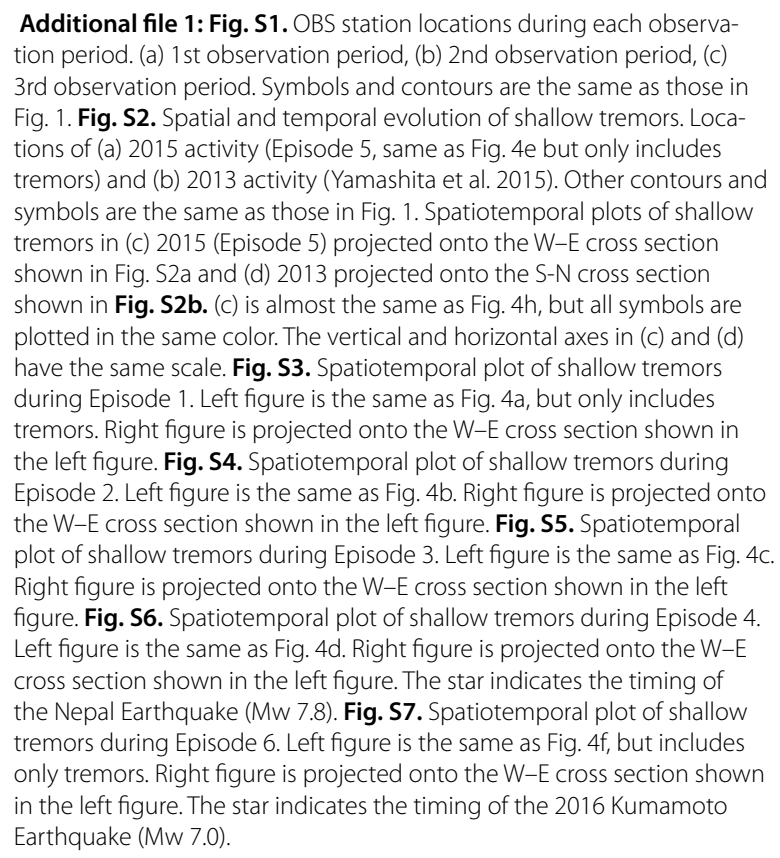

Additional file 2. Shallow tremor catalog detected by OBS data.

\section{Acknowledgements}

We would like to express our gratitude to the technicians at Earthquake Research Institute (ERI), The University of Tokyo, for their support regarding the seafloor observations. We thank the crews of the RN Kaiyomaru Nos. 3, 5, and 7 (Kaiyo Engineering Co.) for their skillful work. Drs. T. Tonegawa and Y. Yamamoto of the Japan Agency for Marine-Earth Science and Technology kindly provided the VLFE catalog and information on the subducted Kyushu-Palau Ridge, respectively. Drs. K. Obara, H. Shiobara, K. Mochizuki of ERI, T. Maeda of Hirosaki University, and R. Takagi of Tohoku University provided helpful comments. We used earthquake catalog data processed by the JMA. All figures were created using the GMT software package version 4 (Wessel and Smith 1998). We also thank two anonymous reviewers and the Editor Dr. D. Shelly for careful reviewing and constructive comments.

\section{Authors' contributions}

YY analyzed the waveform data and wrote the manuscript. YY and MS interpreted the results. All authors designed the seafloor observations, contributed to data acquisition. All authors read and approved the final manuscript.

\section{Funding}

This study was conducted as part of the "Research project for compound disaster mitigation on the great earthquakes and tsunamis around the Nankai Trough region" funded by the Ministry of Education, Culture, Sports, Science, and Technology (MEXT) of Japan. This study is also supported by JSPS KAKENHI Grant Numbers JP16H06473, JP17K01328, JP20K14579.

\section{Availability of data and materials}

Shallow tremor catalogs provided in the Additional information (Additional file 2) and can be downloaded from the Slow Earthquake Database (Kano et al. 2018) (http://www-solid.eps.s.u-tokyo.ac.jp/ sloweq/). The OBS waveform datasets are available from the corresponding author upon request.

\section{Declarations}

Ethics approval and consent to participate Not applicable.

\section{Consent for publication}

Not applicable.

\section{Competing interests}

The authors declare no competing interests.

\section{Author details}

${ }^{1}$ Miyazaki Observatory, Disaster Prevention Research Institute, Kyoto University, 3884 Kaeda, Miyazaki 889-2161, Japan. ${ }^{2}$ Earthquake Research Institute, The University of Tokyo, 1-1-1 Yayoi, Bunkyo-ku, Tokyo 113-0032, Japan.

Received: 25 August 2021 Accepted: 17 October 2021

Published online: 25 October 2021

\section{References}

Ando R, Takeda N, Yamashita T (2012) Propagation dynamics of seismic and aseismic slip governed by fault heterogeneity and Newtonian rheology. J Geophys Res. https://doi.org/10.1029/2012JB009532

Annoura S, Hashimoto T, Kamaya N, Katsumata A (2017) Shallow episodic tremor near the Nankai Trough axis off southeast Mie prefecture. Japan Geophys Res Lett 44(8):3564-3571. https://doi.org/10.1002/2017gl073006

Araki E, Saffer DM, Kopf AJ, Wallace LM, Kimura T, Machida Y, Ide S, Davis E, IODP Expedition 365 shipboard scientists IODP Expedition 365 shipboard scientists (2017) Recurring and triggered slow-slip events near the trench at the Nankai Trough subduction megathrust. Science 356(6343):11571160. https://doi.org/10.1126/science.aan3120

Ariyoshi K, Nakata R, Matsuzawa T, Hino R, Hori T, Hasegawa A, Kaneda Y (2014) The detectability of shallow slow earthquakes by the Dense Oceanfloor Network system for Earthquakes and Tsunamis (DONET) in Tonankai district, Japan. Marine Geophys Res 35(3):295-310. https://doi.org/10. 1007/s11001-013-9192-6

Asano Y, Obara K, Matsuzawa T, Hirose H, Ito Y (2015) Possible shallow slow slip events in Hyuga-nada, Nankai subduction zone, inferred from migration of very low frequency earthquakes. Geophys Res Lett 42(2):331-338. https://doi.org/10.1002/2014gl062165

Baba S, Takemura S, Obara K, Noda A (2020) Slow earthquakes illuminating interplate coupling heterogeneities in subduction zones. Geophys Res Lett 47(14):e2020GL088089. https://doi.org/10.1029/2020GL088089

Bürgmann R, Kogan MG, Steblov GM, Hilley G, Levin VE, Apel E (2005) Interseismic coupling and asperity distribution along the Kamchatka subduction zone. J Geophys Res 110(B7):B07405. https://doi.org/10.1029/2005JB003648

Chao K, Obara K (2016) Triggered tectonic tremor in various types of fault systems of Japan following the 2012 Mw8.6 Sumatra earthquake. J Geophys Res 121(1):170-187. https://doi.org/10.1002/2015JB012566 
Ghosh A, Vidale JE, Sweet JR, Creager KC, Wech AG, Houston H, Brodsky EE (2010) Rapid, continuous streaking of tremor in Cascadia. Geochem Geophy Geosy. https://doi.org/10.1029/2010GC003305

Hirose H, Asano Y, Obara K, Kimura T, Matsuzawa T, Tanaka S, Maeda T (2010) Slow earthquakes linked along dip in the Nankai subduction zone. Science 330(6010):1502. https://doi.org/10.1126/science.1197102

Houston H, Delbridge BG, Wech AG, Creager KC (2011) Rapid tremor reversals in Cascadia generated by a weakened plate interface. Nat Geosci 4(6):404-409. https://doi.org/10.1038/ngeo1157

Ide S (2008) A Brownian walk model for slow earthquakes. Geophys Res Lett 35(17):L17301. https://doi.org/10.1029/2008gl034821

Ito Y, Obara K, Shiomi K, Sekine S, Hirose H (2007) Slow earthquakes coincident with episodic tremors and slow slip events. Science 315(5811):503-506. https://doi.org/10.1126/science.1134454

Ito Y, Hino R, Suzuki S, Kaneda Y (2015) Episodic tremor and slip near the Japan Trench prior to the 2011 Tohoku-Oki earthquake. Geophys Res Lett 42(6):1725-1731. https://doi.org/10.1002/2014gl062986

Kanazawa T, Shinohara M, Shiobara H (2009) Recent progress in seafloor earthquake observations and instruments in Japan. Jishin 2(61):S55-S68

Kaneko L, Ide S, Nakano M (2018) Slow Earthquakes in the Microseism Frequency Band $(0.1-1.0 \mathrm{~Hz})$ off Kii Peninsula. Japan. Geophys Res Lett 45(6):2618-2624. https://doi.org/10.1002/2017gl076773

Kano M, Aso N, Matsuzawa T, Ide S, Annoura S, Arai R, Baba S, Bostock M, Chao K, Heki K, Itaba S, Ito Y, Kamaya N, Maeda T, Maury J, Nakamura M, Nishimura T, Obana K, Ohta K, Poiata N, Rousset B, Sugioka H, Takagi R, Takahashi T, Takeo A, Tu Y, Uchida N, Yamashita Y, Obara K (2018) Development of a slow earthquake database. Seismol Res Lett 89(4):1566-1575. https://doi.org/10.1785/0220180021

Luo Y, Liu Z (2021) Fault zone heterogeneities explain depth-dependent pattern and evolution of slow earthquakes in Cascadia. Nat Commun 12(1):1959. https://doi.org/10.1038/s41467-021-22232-x

Maeda T, Obara K (2009) Spatiotemporal distribution of seismic energy radiation from low-frequency tremor in western Shikoku, Japan. J Geophys Res 114:B00A09. https://doi.org/10.1029/2008jb006043

Miyazawa M, Brodsky EE (2008) Deep low-frequency tremor that correlates with passing surface waves. J Geophys Res 113(B1):B01307. https://doi. org/10.1029/2006JB004890

Miyazawa M, Mori J (2005) Detection of triggered deep low-frequency events from the 2003 Tokachi-oki earthquake. Geophys Res Lett 32(10):L10307. https://doi.org/10.1029/2005GL022539

Nakanishi A, Takahashi N, Yamamoto Y, Takahashi T, Ozgur Citak S, Nakamura T, Obana K, Kodaira S, Kaneda Y (2018) Three-dimensional plate geometry and P-wave velocity models of the subduction zone in SW Japan: Implications for seismogenesis. In: Byrne T, Underwood MB, III, Fisher $D$ et al. (eds) Geology and Tectonics of Subduction Zones: A Tribute to Gaku Kimura, vol 534. Special Paper of the Geological Society of America. doi:https://doi.org/10.1130/2018.2534(04)

Nakano M, Hori T, Araki E, Kodaira S, Ide S (2018) Shallow very-low-frequency earthquakes accompany slow slip events in the Nankai subduction zone. Nat Commun 9(1):984. https://doi.org/10.1038/s41467-018-03431-5

Nishikawa T, Matsuzawa T, Ohta K, Uchida N, Nishimura T, Ide S (2019) The slow earthquake spectrum in the Japan Trench illuminated by the S-net seafloor observatories. Science 365(6455):808-813. https://doi.org/10. 1126/science.aax5618

Obana K, Kodaira S (2009) Low-frequency tremors associated with reverse faults in a shallow accretionary prism. Earth Planet Sci Lett 287(1-2):168174. https://doi.org/10.1016/j.epsl.2009.08.005

Obara K (2002) Nonvolcanic deep tremor associated with subduction in southwest Japan. Science 296(5573):1679-1681. https://doi.org/10.1126/ science. 1070378

Obara K (2010) Phenomenology of deep slow earthquake family in southwest Japan: spatiotemporal characteristics and segmentation. J Geophys Res. https://doi.org/10.1029/2008jb006048

Obara K, Ito Y (2005) Very low frequency earthquakes excited by the 2004 off the Kii peninsula earthquakes: a dynamic deformation process in the large accretionary prism. Earth Planets Space 57(4):321-326. https://doi, org/10.1186/Bf03352570

Obara K, Kato A (2016) Connecting slow earthquakes to huge earthquakes. Science 353(6296):253-257. https://doi.org/10.1126/science.aaf1512

Ohta K, Ito Y, Hino R, Ohyanagi S, Matsuzawa T, Shiobara H, Shinohara M (2019) Tremor and inferred slow slip associated with afterslip of the 2011 Tohoku
Earthquake. Geophys Res Lett 46(9):4591-4598. https://doi.org/10.1029/ $2019 \mathrm{gl} 082468$

Plata-Martinez R, Ide S, Shinohara M, Garcia ES, Mizuno N, Dominguez LA, Taira T, Yamashita Y, Toh A, Yamada T, Real J, Husker A, Cruz-Atienza VM, Ito Y (2021) Shallow slow earthquakes to decipher future catastrophic earthquakes in the Guerrero seismic gap. Nat Commun 12(1):3976. https://doi. org/10.1038/s41467-021-24210-9

Schwartz SY, Rokosky JM (2007) Slow slip events and seismic tremor at circumpacific subduction zones. Rev Geophys 45(3):RG3004. https://doi.org/10. 1029/2006rg000208

Shelly DR, Beroza GC, Ide S (2007) Complex evolution of transient slip derived from precise tremor locations in western Shikoku, Japan. Geochem Geophys Geosyst 8(10):Q10014. https://doi.org/10.1029/2007gc001640

Tanaka S, Matsuzawa T, Asano Y (2019) Shallow low-frequency tremor in the Northern Japan trench subduction zone. Geophys Res Lett 46(10):52175224. https://doi.org/10.1029/2019gl082817

Todd EK, Schwartz SY, Mochizuki K, Wallace LM, Sheehan AF, Webb SC, Williams CA, Nakai J, Yarce J, Fry B, Henrys S, Ito Y (2018) Earthquakes and tremor linked to seamount subduction during shallow slow slip at the Hikurangi Margin, New Zealand. J Geophys Res 123:6769-6783. https://doi.org/10. 1029/2018jb016136

Tonegawa T, Yamashita Y, Takahashi T, Shinohara M, Ishihara Y, Kodaira S, Kaneda Y (2020) Spatial relationship between shallow very low frequency earthquakes and the subducted Kyushu-Palau Ridge in the Hyuga-nada region of the Nankai subduction zone. Geophys J Int 222(3):1542-1554. https://doi.org/10.1093/gji/ggaa264

Uchida N, Takagi R, Asano Y, Obara K (2020) Migration of shallow and deep slow earthquakes toward the locked segment of the Nankai megathrust. Earth Planet Sci Lett 531:115986. https://doi.org/10.1016/j.epsl.2019. 115986

Wallace LM, Webb SC, Ito Y, Mochizuki K, Hino R, Henrys S, Schwartz SY, Sheehan AF (2016) Slow slip near the trench at the Hikurangi subduction zone, New Zealand. Science 352(6286):701-704. https://doi.org/10.1126/ science.aaf2349

Wang KL, Bilek SL (2014) Invited review paper: fault creep caused by subduction of rough seafloor relief. Tectonophysics 610:1-24. https://doi.org/10. 1016/j.tecto.2013.11.024

Wessel P, Smith WHF (1998) New, improved version of generic mapping tools released. Eos Trans AGU 79(47):579-579. https://doi.org/10.1029/98EO0 0426

Yagi Y, Kikuchi M, Yoshida S, Sagiya T (1999) Comparison of the coseismic rupture with the aftershock distribution in the Hyuga-nada earthquakes of 1996. Geophys Res Lett 26(20):3161-3164. https://doi.org/10.1029/ 1999gl005340

Yagi Y, Kikuchi M, Yoshida S, Yamanaka Y (1998) Source process of the Hyuganada earthquake of April 1, 1968 (MJMA 7.5), and its relationship to the subsequent seismicity. Zisin. 51(1):139-148. https://doi.org/10.4294/zisin 1948.51.1_139

Yamamoto Y, Obana K, Takahashi T, Nakanishi A, Kodaira S, Kaneda Y (2013) Imaging of the subducted Kyushu-Palau Ridge in the Hyuga-nada region, western Nankai Trough subduction zone. Tectonophysics 589:90-102. https://doi.org/10.1016/j.tecto.2012.12.028

Yamashita Y, Shimizu H, Goto K (2012) Small repeating earthquake activity, interplate quasi-static slip, and interplate coupling in the Hyuga-nada, southwestern Japan subduction zone. Geophys Res Lett 39(8):L08304. https://doi.org/10.1029/2012gl051476

Yamashita Y, Yakiwara H, Asano Y, Shimizu H, Uchida K, Hirano S, Umakoshi K, Miyamachi H, Nakamoto M, Fukui M, Kamizono M, Kanehara H, Yamada T, Shinohara M, Obara K (2015) Migrating tremor off southern Kyushu as evidence for slow slip of a shallow subduction interface. Science 348(6235):676-679. https://doi.org/10.1126/science.aaa4242

Yokota Y, Ishikawa T (2020) Shallow slow slip events along the Nankai Trough detected by GNSS-A. Sci Adv 6(3):eaay5786. https://doi.org/10.1126/ sciadv.aay 5786

\section{Publisher's Note}

Springer Nature remains neutral with regard to jurisdictional claims in published maps and institutional affiliations. 